\title{
Protective effect of a novel anti-aging facial cream containing Alteromonas ferment extract and carnosine against environmental pollution in human skin explants in ex-vivo study
}

\author{
Narda M. and Granger C. \\ Innovation and Development, ISDIN, Barcelona, Spain
}

\section{INTRODUCTION}

Environmental pollution in the form of fine or very fine particulate matter (PM2.5) from vehicle exhaust and industrial fumes are recognized as causing premature aging, acne and hyperpigmentation in exposed skin. A novel anti-aging facial cream with alteromonas ferment extract, carnosine and niacinamide (FC-AFE) has been designed to protect against the damage of pollution, reduce advanced glycation end-products and reduce jawline sagging

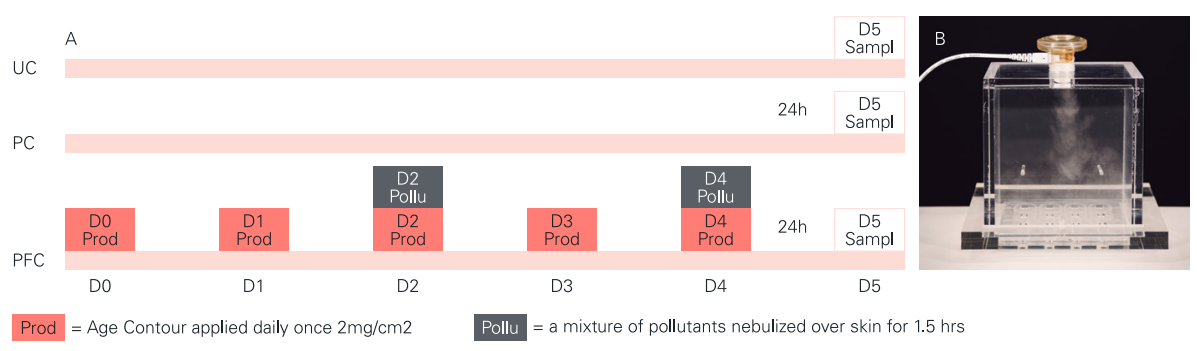

Figure 1. Study design (A) and chamber used to expose skin explants to nebulized diesel particles (B) fítico

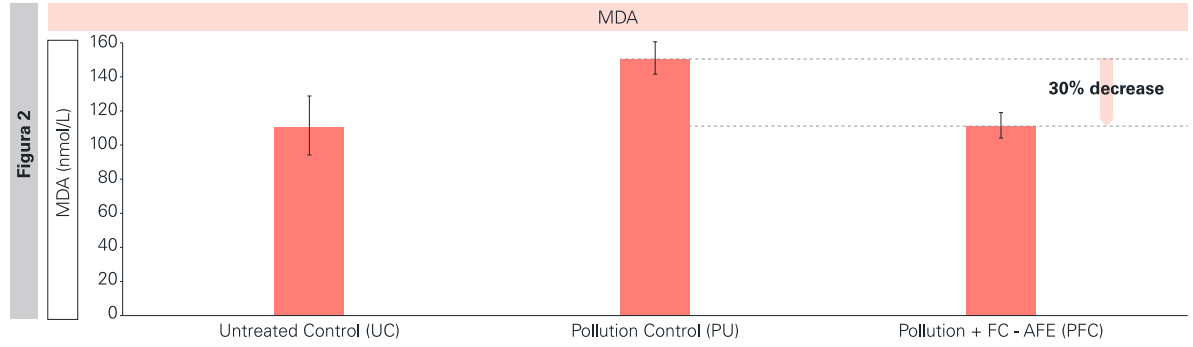

Figure 2. MDA levels (nmol/L) in untreated control (UC), pollution control (PC) and pollution+FC-AFE (PFC).

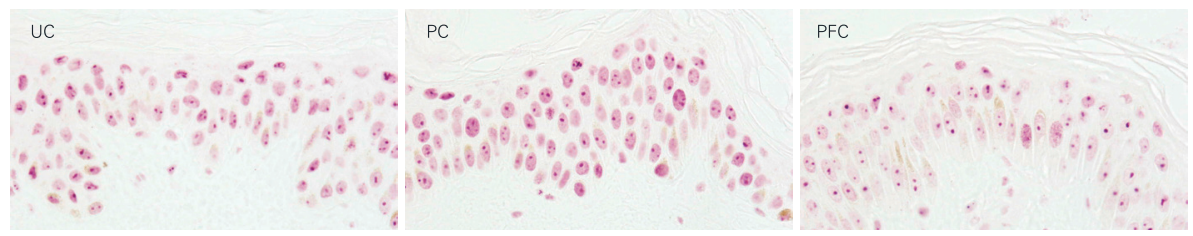

Figure 3. Histological skin sections immunostained with nuclear and activated form of Nrf2 in untreated control (UC), pollution control (PC) and pollution+FC-AFE (PFC)
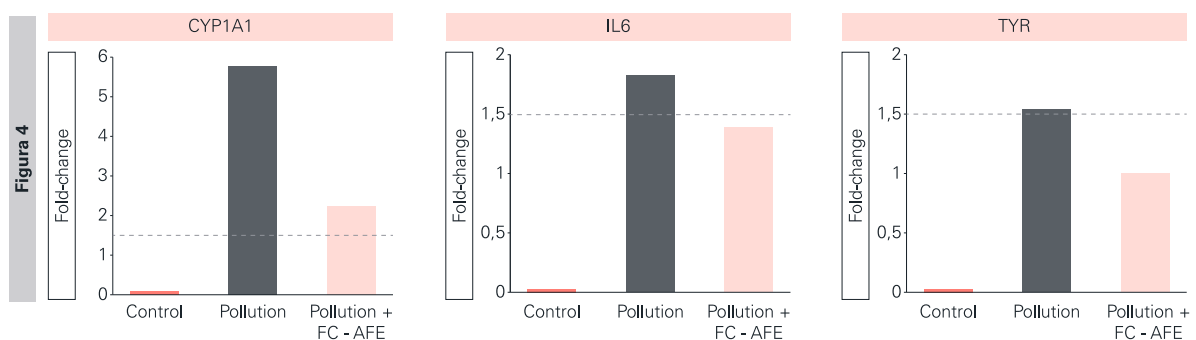

Figure 4. Levels of CYP1A1, IL6 and TYR in skin sections in untreated control (e) pollution control (•) and pollution+FC-AFE (). Results expressed as fold changes with respect to UC group. Only changes atleast 1.5 fold (indicated by red line) or higher were considered relevant.

OBJECTIVE
This ex-vivo study looks to establish the effects of pollution and the protective effects of the novel METHOD

Human skin explants were obtained from abdominoplasty and assigned to one of three treatment groups: untreated control (UC), pollution control (PC) and pollution+FC-AFE (PFC). On day 0 